\title{
Ver e Narrar: verbos para fotolivros ${ }^{1}$
}

Daniela Nery Bracchi ${ }^{2}$

Resumo: Examinamos neste artigo duas perspectivas que podem ser empregadas para a compreensão dos fotolivros e as discutimos em relação às publicações que tratam da fotopintura e do álbum de família. Enquanto o ponto de vista da visualidade interroga a forma visível do retrato pintado em continuidade com outras linguagens artísticas, 0 entendimento das práticas sociais que estabelecem os usos e circulação das imagens dos álbuns da família faz parte de uma abordagem potente para nos aproximarmos desses materiais.

Palavras-chave: Fotolivros. Fotopintura. Visualidade. Linguagens artísticas. Álbuns.

Quando falamos sobre fotografia, sabemos que uma imagem pode responder muitas coisas a depender da pergunta que fazemos para ela. Evitaremos, então, investigar os "falsos problemas" que Régis Durand (1995, p. 36) nos alerta que podemos colocar frente à fotografia. "É ou não é uma arte? Uma arte menor? Uma arte 'intermediária'?... o que é uma 'verdadeira' fotografia? Aquela que é 'pura' (direta, não manipulada), e que se oporá então a uma fotografia 'impura' (manipulada, construída)?"

Podemos entrever uma baliza nos falsos problemas apontados por Durand. De um lado, há pouco rendimento em diluir as questões que podemos fazer a uma imagem fotográfica no campo infindável da arte. Por outro lado, estreitarmos demais nossas indagações sobre a fotografia pura não nos leva muito longe no modo de compreender as imagens.

Buscando um caminho do meio, o percurso trilhado aqui entenderá a fotografia a partir das condições de visibilidade das imagens. Isso porque entendemos que é dentro do campo comum do visível e do âmbito específico das práticas sociais de que a fotografia participa que podemos compreender as narrativas fotográficas apresentadas no formato de livro.

\footnotetext{
${ }^{1}$ Artigo publicado inicialmente na Base de Dados de Livros de Fotografia, em outubro de 2020.

2 Pesquisadora do Núcleo de Design e Comunicação da UFPE - Centro Acadêmico do Agreste. E-mail: daniela.bracchi@ufpe.br
} 


\section{Crisang

Quando adentramos o terreno da visibilidade, o tópico que chama mais atenção é o do diálogo entre as diferentes linguagens visuais. As artes visuais inauguram modos de ver que se reapresentam em muitas publicações fotográficas, convocando-nos a observar o que cada campo traz de aporte para o outro. É um jogo de similaridades e diferenças muito bem visto em livros de fotografia como Types, de Fernando Banzi, Interior profundo (sobre as fotografias de Mestre Júlio Santos) e Estes outros (compilação de imagens da coleção Titus Riedl). São publicações que refletem sobre os imbricamentos da visualidade fotográfica e pictórica e sobre a presença dessas imagens no seio social. Elas nos indagam sobre sua utilidade, como circulavam e de que modo conviviam com as pessoas na parede da sala.

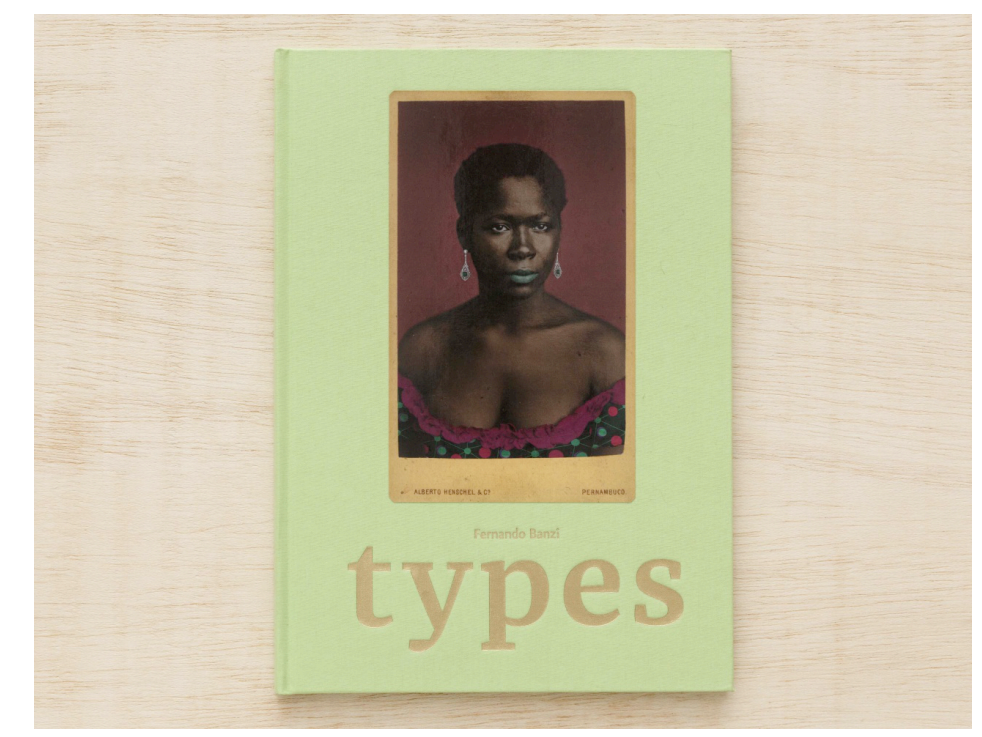

BANZI, Fernando. Types. Paris: Editions Bessard, 2019. 


\section{Criseng Crises}

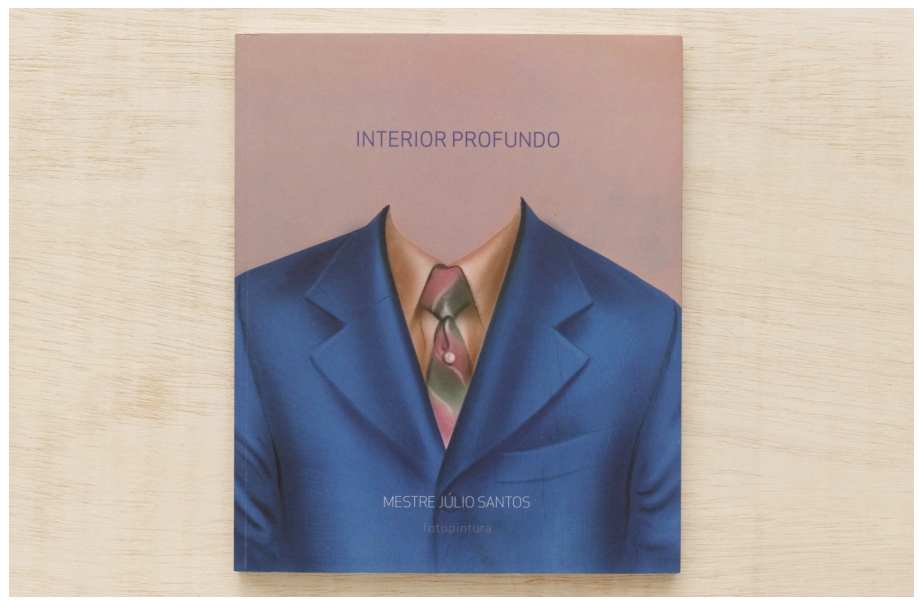

SANTOS, Júlio. Interior profundo: Mestre Júlio Santos, fotopintura. Fortaleza: Tempo D'Imagem; São Paulo: Pinacoteca do Estado de São Paulo, 2012.

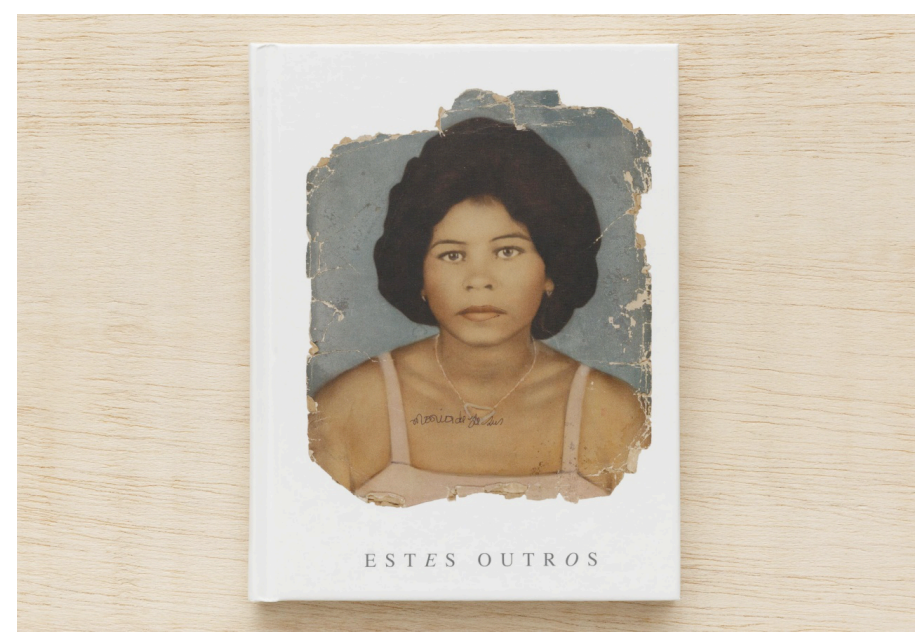

LINSKER, Roberto (org.). Estes outros: fotopinturas da coleção Titus Riedl. São Paulo: Terra Virgem, 2016.

Elejo este tipo de imagem, a fotopintura, porque nela podemos perceber a fotografia dentro de um contínuo, de um espectro de visualidade no qual a pintura e outras artes visuais tem muito a contribuir. Nas relações que podemos ir tecendo entre essas formas artísticas há aspectos estritamente visuais e outros nem tanto, que se referem ao papel social e subjetivo que essas imagens podem alcançar.

A princípio, utilizar a intervenção da pintura sobre fotografias poderia sugerir a ideia de devolver à imagem algo que a fotografia não teria podido expressar. Mas não nos referimos aqui apenas a uma certa limitação técnica que pode ser inferida dos retratos em preto e branco e seu afastamento das cores realistas do mundo. Na fotopintura há 


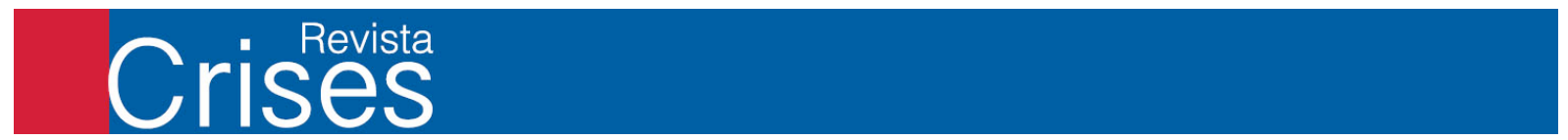

também a inserção de elementos do mundo que agora podem habitar a imagem e constituir o sujeito de outra forma.

Nas relações visuais entre fotografia e pintura, sabemos que as cores das tintas e as intervenções manuais são capazes de levar essas imagens a um outro campo de sentido. O próprio Banzi defende aqui que a intervenção da pintura sobre os carte de visite permite trazer uma maior pessoalidade e resgatar individualidades expressas em tons diferentes de pele, cores, texturas e roupas próprias de cada um dos retratos que sofrem sua intervenção.

Reconfigurar o modo visível como esses retratados chegam até nós desloca-os também historicamente da imagem relegada aos escravizados. Essas fotopinturas permitem que eles se mostrem de uma outra maneira e possam ser observados em outros contextos que agora essas fotografias são capazes de circular. Os novos elementos que foram incluídos nela, especialmente as estampas e as roupas, conduzemnos a outros aspectos da identidade dos fotografados, o que faz parte da tentativa de Banzi de aproximá-los do universo cultural de onde foram arrancados pela escravidão.

O que nos chama a atenção ainda em Types é que o autor preserva a moldura das imagens, nas quais podemos ver o nome do estúdio fotográfico de Alberto Henschel (1827 - 1882). Essa marca textual nos permite reconduzir as imagens ao seu contexto de produção, pois Henschel circulou por Pernambuco, Bahia e Rio de Janeiro produzindo cartes de visite que serviam não só para que os mais abastados fizessem sua imagem circular, mas para que as fotos de escravizados os apresentassem em meio ao ambiente do comércio.

Sabemos que essas marcas que encontramos nas bordas das imagens fazem parte dos papéis efêmeros da fotografia, expressão que dá título à pesquisa de Rubens Fernandes Junior sobre cartões, embalagens e outros artigos de papelaria capazes de guardar uma memória do cotidiano das práticas fotográficas no Brasil.

Além de marco histórico e social da produção de imagens em nosso país, essas bordas são molduras que permitem destacar e separar ainda mais a figura do retratado. Enquanto estratégia estética que permite individuar figura e fundo, a função da borda pode ser percebida em outras manifestações artísticas, conforme destaca Scalabroni (2005). A moldura encontra, então, paralelo com outras fronteiras estabelecidas entre o 


\title{
Crisevista

espaço da obra artística e do público, como o pedestal da escultura e ainda os elementos editoriais que gravitam o espaço gráfico da fotografia. Talvez o mais famoso exemplo no mundo dos fotolivros seja Hustlers, de Philip-Lorca diCorcia, no qual a moldura ocupa um espaço desproporcional ao que costumamos encontrar nesse tipo de publicação.

Retornando às fotopinturas, mas dessa vez num contexto mais popular, percebemos nas fotografias de Mestre Júlio que as fotopinturas ocupam certos lugares sociais, exercem algumas funções ao conviverem com a família na parede da sala. Em publicações como Interior profundo, catálogo da exposição realizada na Pinacoteca de São Paulo em 2012, a inserção de cores e formas pintadas nas fotos nos mostram a possibilidade de acesso a outros modos de ser visto. Novas roupas, cabelos e acessórios que as próprias pessoas escolhiam, ou eram indicados por aqueles que viabilizavam a produção dessas imagens, podem ser entendidos como forma de imaginação de uma outra imagem social. É o que nos lembra o pesquisador Eduardo Queiroga (2017, p. 11).

\begin{abstract}
Muitas vezes a encomenda de uma imagem idealizada, que passa pelo embelezamento da pessoa - retirada de rugas ou outros sinais indesejáveis, escolha de vestimentas que não fazem parte do cotidiano do retratado - cumpre o papel de diminuir a desigualdade social, de parecer pertencer a uma classe social mais abastada, de apagar - ao menos na memória familiar - sua situação mais humilde.
\end{abstract}

É, portanto, um imaginar-se e tornar-se a imagem de um ideal social. No diálogo entre a verossimilhança fotográfica e a oportunidade que a pintura traz de sintetizar outros elementos da imagem, percebemos novos aspectos do mundo visível. Ver é o verbo transformado por essas imagens que nos permitem olhar novas cores, formas e identidades sociais.

\section{Narrar para além do ver: fotografia e cena social}

As publicações de que falamos até aqui nos levam à interrogação sobre os diferentes papéis sociais que uma fotopintura pode ter nas paredes da sala de uma família ou de uma galeria de arte. Se a imagem participa de diferentes situações, podemos questionar seu papel social quando circula na forma de livros de fotografia. Aqui, mais uma vez o contexto doméstico e familiar pode trazer situações muito diversas 


\section{Crisevista

daquelas do âmbito artístico e editorial do qual muitos dos novos fotolivros participam.

Quando alguém confeccionava um álbum fotográfico antes do fenômeno editorial dos fotolivros comerciais que vemos atualmente, essa pessoa se aventurava a ordenar as fotos, lembranças e dados numa narrativa que ia ganhando contornos próprios. Esses álbuns não eram unicamente do tipo que continham memórias familiares, mas existem também os álbuns de viagem, por exemplo. Na publicação Photographic Memory (CURTIS, 2011), podemos conhecer as imagens e textos que compunham Alaska, álbum que narra a expedição patrocinada por Edward H. Harriman em 1899 às terras longínquas e geladas do estado americano. Dados científicos, mapas e fotografias dos familiares de Harriman na expedição misturam-se num modo de exposição bastante peculiar da história da viagem.

Quanto ao álbum de família, temos um belo estudo realizado por Armando Silva, publicado em 2008. Em suas pesquisas, Silva nos traz à consciência uma figura central do contexto no qual os álbuns circulavam: o narrador. Era ele quem possibilitava àquelas imagens serem vistas ao lado de memórias, impressões e afetos partilhados enquanto se folheavam as páginas.

O pesquisador traz ainda a interessante consideração de que há mudanças nos tons e histórias que eram narradas enquanto se via o álbum a depender do sexo e idade dos sujeitos retratados e dos narradores. Sabe-se, então, que as imagens de família costumavam ser vistas dentro de uma determinada cena social na qual as lembranças e emoções são rememoradas pelo "narrador do álbum". As imagens do álbum de família eram permeadas por essa atmosfera de narração e diálogo, de modo que os sujeitos inseridos em sua cena social de fruição tornavam-se ativos narradores de memórias, impressões e emoções.

Algo um pouco diverso do que entendemos ser o contexto de leitura dos fotolivros que integram mais fortemente a cena artística. Eles se aproximam muito mais do tipo de recepção individual que temos no romance e na literatura, que guardam devaneios individuais ao longo de sua apreciação.

Essas diferenças colocadas até aqui servem para explicitar dois pontos de vista sob os quais proponho que os livros de fotografia sejam compreendidos. O primeiro diz respeito à localização da imagem no universo contínuo do visível que a faz dialogar com 


\section{Criseng

outras artes, como a pintura. E não há motivo para nos restringirmos aos diálogos entre a imagem fotográfica e pictural. Podemos tecer relações entre a fotografia e o campo do cinema, literatura, etc. Sabemos que esse diálogo se dá nas negociações sobre outros modos de ver e compreender o mundo.

Mas fizemos questão de convocar nesse artigo um segundo ponto de vista: o das práticas sociais. Isso porque a fotografia, a partir da materialidade na qual circula (e aqui em especial os livros de fotografia), participará de modo diferente de uma situação social. A ideia de cena aqui é bem-vinda pela evocação da ideia teatral de atores que precisam estar em interação num determinado contexto para que o discurso seja construído.

Passemos então a problematizar o ver e o narrar, pois esse é um duplo ponto de vista a partir do qual poderemos interrogar os fotolivros. São questões mais justas de serem colocadas e talvez questões mais verdadeiras na concepção de Durand, que abriu esse artigo nos alertando sobre os falsos problemas que interpomos às fotografias.

\section{REFERÊNCIAS}

BANZI, Fernando. Types. Paris: Editions Bessard, 2019.

CURTIS, Verna Posever. Photographic Memory: The Album in the Age of Photography Nova York: Aperture/Library of congress, 2011.

DURAND, Régis. Le Temps de I'Image. Essai sur les Conditions d'une Histoire des Formes Photographiques. Paris: La Différence, 1995.

LINSKER, Roberto (org.). Estes outros: fotopinturas da coleção Titus Riedl. São Paulo: Terra Virgem, 2016.

QUEIROGA, Eduardo. FOTOPINTURA CONTEMPORÂNEA: a pós-produção no trabalho de Mestre Júlio. Cartema. v.6, nº 6. 2017.

SANTOS, Júlio. Interior profundo: Mestre Júlio Santos, fotopintura. Fortaleza: Tempo D'Imagem; São Paulo: Pinacoteca do Estado de São Paulo, 2012.

SCALABRONI, Luisa. "Forme e ruoli della cornice nella rappresentazione pittorica. IN: EC Rivista dell'Associazione Italiana Studi Semiotici online. $\mathrm{n}^{\circ} 2$, jan. 2005.

SILVA, Armando. Álbum de família: a imagem de nós mesmos. São Paulo: SENAC, SESC, 2008. 